\title{
Three Problematic Aspects of Analytical Aesthetics
}

\author{
Anders Pettersson
}

\section{I}

There are certain aspects of analytical aesthetics that, over the years, I have increasingly come to see as problematic: its insufficient concern for relevant empirical facts, its tendency to objectivize concepts, and its tendency to believe in the existence of privileged perspectives on the world. In this paper, I will illustrate and discuss these features, drawing my examples from three publications by prominent exponents of analytical aesthetics: Peter Lamarque and Stein Haugom Olsen's Truth, Fiction, and Literature: A Philosophical Perspective (1994), Jerrold Levinson's “Extending Art Historically" (1993), and Noël Carroll's "Art and Human Nature" (2004). Although I will comment on some of the theses explicitly advocated in the three contributions - which are all concerned with the concepts of literature or of art - my main focus will be on what they do not mention, on what I consider to be some of their blind spots.

My claim that the three alleged weaknesses are frequently to be found in analytical aesthetics cannot really be substantiated within the confines of a single article. I will, however, be more than satisfied if I am able to convince some analytical aestheticians that these three features are in fact problematic. That, rather than the question of how widespread they are, is probably the really contentious issue.

\section{II}

In Truth, Fiction, and Literature, Peter Lamarque and Stein Haugom Olsen describe the reading of literature as a practice governed by a set of conventions. They write:

Adopting the literary stance towards a text is to identify it as a literary work and apprehend it in accordance with the conventions of the literary practice. The mode of apprehension which the practice defines is one of appreciation. The literary stance is defined by the expectation of (and consequently the at- 
tempt to identify) a certain type of value, i.e. literary aesthetic value, in the text in question. ${ }^{1}$

The authors describe literary works as, ideally, capable of affording literary aesthetic value. In their opinion, reading literature in accordance with the conventions of the literary practice is to seek to identify and benefit from the literary aesthetic value of the text. "Aesthetic" is to be understood, here, in a narrow and specific sense: Lamarque and Olsen defend the idea of the autonomy of literature and deny that literary appreciation includes the forming of beliefs about the world outside the text. ${ }^{2}$

Personally, I do not subscribe to Lamarque and Olsen's analysis of the conventions of the literary practice. However, in the present context it is one of their implicit methodological suppositions that is at issue, rather than the substance of their account. Lamarque and Olsen offer their characterization of the literary stance without citing any empirical evidence in its favour - as a reader of their book, one gains the impression that their basis is their own inside knowledge of the practice and philosophical reflection. It is as if empirical evidence about the attitudes actually adopted by readers of literature were superfluous - but an account of the conventions of the literary practice cannot very well be independent of facts about how the practice is actually performed.

In empirical investigations into the reading of literature, readers are sometimes invited to indicate what kinds of satisfaction they seek in literature. For instance, in 2001, Michael Charlton and his associates carried out an extensive investigation of German novel readers (1,025 interviewees). ${ }^{3}$ At one point in the interviews, the subjects were asked "For what reasons do you read novels? Do you read novels ..." and were offered eight possible grounds which they could mention or not mention as relevant in their own case. (They were also allowed to add further reasons of their own or to say that they did not know. ${ }^{4}$ ) The eight grounds, and the percentages of positive answers (that is, of mentions), were as follows: ${ }^{5}$

To entertain yourself

To relax

To do something for your all-round education

Because the theme gives impulses to reflection

Because you enjoy the style of the author

To learn something about people

To be transported into another world

To be able to talk with others about them

$$
\begin{aligned}
& 75.2 \% \\
& 74.5 \% \\
& 63.7 \% \\
& 58.0 \% \\
& 58.0 \% \\
& 57.9 \% \\
& 51.1 \% \\
& 43.9 \%
\end{aligned}
$$


Largely compatible results were obtained in Hintzenberger, Schmidt, and Zobel's West German investigation from 1978-79, and in a Norwegian study by Jofrid Karner Smidt published in $2002 .^{6}$

It is true that "To enjoy the autonomous literary-aesthetic value of the work" was not on Charlton's list. Nevertheless, the outcome appears difficult to reconcile with the idea that readers of literature concentrate on appreciation in Lamarque and Olsen's sense: that would be inconsistent with the role seemingly played by pure entertainment ("entertain yourself", "relax") and by learning from literature ("education", "learn something").

No pre-established alternatives were used in the pilot study for an investigation by H.W.J. Miesen, finally reported in 2003. Miesen elicited beliefs about the reading of novels from 33 visitors to a local Dutch library. He used a questionnaire and submitted the answers given to content analysis. According to Miesen's subjects, their main reasons for reading literature were (as categorized by Miesen, and listed here in random order):

To experience feelings of beauty

To stimulate one's imagination

To be surprised

To entertain oneself

To learn more about others

To get a different view of things

To sharpen one's intellectual capacity

To read real-life stories

To have a clear view of how to live ${ }^{7}$

Seemingly, a kind of aesthetic motive in a narrow sense is present in Miesen's subjects ("experience feelings of beauty"), just as it was in Charlton's study ("enjoy the style of the author"). However, most of the reasons mentioned are of entirely different kinds.

Judging by the results just reviewed, readers of literature do not, on the whole, adopt the attitude that Lamarque and Olsen characterize as the literary stance. To a large extent, they appear to be looking for such things as sheer enjoyment, knowledge of the world, enhancement of their intellectual capacities, and understanding of other people and of themselves. These empirical results may naturally be relativized, or even questioned, on various grounds. On the other hand, Lamarque and Olsen's view is entirely without systematic empirical support of any kind.

Clearly, the empirical investigations do not in themselves disprove Lamarque and Olsen's statements. Lamarque and Olsen wish to character- 
ize the conventions of the literary practice, and such an undertaking will inevitably involve a measure of idealization, perhaps also a measure of normativity. Yet, as I pointed out earlier, it is difficult to see how one can simply neglect, in giving an account of literary practice, how readers actually read literature. Compare, for instance, an account of the grammatical conventions of English. It would not be a simple reflection of how speakers and writers of the language express themselves, for many actual utterances will no doubt be considered ungrammatical, and for good reasons. But such an account cannot cut all ties with actual usage either, for it would become idiosyncratic and counterproductive if the purported grammatical conventions were not in fact followed, more or less, in linguistic utterances considered fully acceptable within the community of native English speakers.

For that reason I find it a crucial shortcoming in Lamarque and Olsen that they make no attempt to substantiate the tenability of their account of the literary practice through reference to empirical findings. They do not even seem to think of empirical evidence as something that is missing from their argument, something that, for example, they hope will be forthcoming eventually, through their own efforts or through those of other researchers.

Their silence on this point would have been understandable if it had been evident and generally known that the attitude they describe as the literary stance is indeed the stance adopted by readers of literature: that these are more or less invariably concentrated on deriving autonomous literary-aesthetic value from their acts of reading. However, the brief look at some empirical studies of readers' motivation must at least be said to demonstrate that such an assumption is highly contestable. Hence, to me, the characterization of the literary stance in Truth, Fiction, and Literature is a pertinent example of the insufficient concern for the empirical - for empirical circumstances that can be reasonably supposed to be relevant to the philosophical argument - that I often find in analytical aesthetics.

\section{III}

I now turn to the objectivizing of concepts, which I will exemplify with the help of Jerrold Levinson's "Extending Art Historically", one of the essays in which Levinson explains and defends his so-called historical definition of art. For my purposes, it will not be necessary to discuss the actual content of the definition. What interests me here are some of Levinson's general intuitions about the concept of art.

As is well known from works such as Paul Kristeller's "The Modern 
System of the Arts" (1951-52) or, much more recently, Larry Shiner's The Invention of Art: A Cultural History (2001), ${ }^{8}$ concepts such as 'art', 'literature', et cetera in something like their modern shape emerged, very broadly speaking, in the course of the 18th century. Levinson notes that the concept of art has passed through a number of historical changes. In the essay, however, he concentrates on our current generic concept of art, "the most general concept of art that we have now, one that seems adequate to the art of today but can also be seen to comprehend all that its predecessors did as well, that is to say, all the art of our past that has ever been recognized as such". ${ }^{9}$ He specifies how he prefers to define that concept, and then goes on to explain why the concept may also be applied to earlier periods.

It is natural to ask at this point what concept of art it is that I have taken myself to have plumbed, or to put the question in its usual, accusatory form, whose? Bearing in mind that it is the descriptive or classificatory idea of art that is in question, and not any of its honorific or polemical relatives, my largely unapologetic answer to this is that it is, naturally enough, our concept - the Western, Renaissance-derived notion whose current state of evolution I was trying to understand ... Our concept of art, the one we standardly work with and presuppose in enlightened and informed contemporary discourse about it, is one we undoubtedly and properly apply outside the historical and cultural sphere in which it was forged ... To put this more pithily, if another culture has art, it must have art in our sense, more or less - whatever the inevitable differences between its art and ours in terms of materials, structure, expressiveness, ritualembeddedness, object-orientedness, and so on. Otherwise the claim, assuming we have not switched languages, has no clear content. ${ }^{10}$

I agree with Levinson that a contemporary concept of art may in principle also be applied to other times and cultures than our own. My reservations concerning his formulations refer to two other, underlying issues, not explicitly addressed by Levinson.

First, the idea that we have, today, a common concept of art ("[o]ur concept of art") is introduced and taken for granted without factual corroboration, although it is absolutely fundamental to Levinson's argument in the article. As in Lamarque and Olsen, I miss any reference to relevant empirical circumstances, in Levinson's case: to the contemporary use of the word "art" and to its functions. In my view, the supposition that there is a common concept of art cannot very well be true independently of how people actually think and speak of art.

When elaborating on this, let me first comment on our concept(s) of 
literature. ${ }^{11}$ There is an everyday use of the word "literature", reflected in such sources as dictionaries. Actually, the word has several meanings, but one could say that there is an everyday concept of literature as an art which we all share, "our concept of literature". Webster defines it as "writings in prose or verse; esp: writings having excellence of form or expression and expressing ideas of permanent or universal interest". ${ }^{12}$

Obviously, however, this communal concept of literature is vague and general. Often we use more precise concepts also labelled "literature", concepts that make the more specialized distinctions we need in various circumstances. This is true of "literature" as used in a number of different historical and systematic contexts within academic literary studies, and of "literature" in certain more specialized non-academic usages: in connection with library classification, in connection with the Nobel Prize in Literature, et cetera. Arguably, these more specialized concepts of literature - mutually different and associated with mutually incompatible requirements on the content of the concept - fulfil their respective, worthwhile functions and are all legitimate.

It is consequently not possible to speak of "our concept of literature" as a single, definite concept, the one we standardly work with and presuppose in enlightened and informed contemporary discourse about it. It also appears difficult to deny that the same must apply to our concept of art, particularly since literature, and the multiplicity of literature just described, de facto falls under the generic concept of art that Levinson has in mind. There is certainly a shared, everyday concept of art, something that "art" means as a part of the English language; The American Heritage Dictionary defines it as "human works of beauty considered as a group". ${ }^{13}$ That vague and general everyday concept will however probably be of little value in serious discussions of the arts, and will not be the one that we use in such demanding contexts.

The idea of human works of beauty considered as a group would, in reality, have to be sharpened and refined considerably if we were to create interesting groupings and generalizations with its help, and such sharpening and refining is something which can only be done by means of stipulation. Stipulation, however, must be performed with some more specific aim in mind if it is not to be wholly arbitrary. This makes it doubtful that one could construe a unified concept of art that would be worth having, because of the multitude of purposes that the concept, or concepts, of art probably serves in enlightened and informed contemporary discourse.

The phrase "worth having" is important here. Construing concepts is easy enough, but construing concepts worth having is not. For me, worth- 
while concepts are those which successfully fulfil significant purposes. I believe in conceptual relativity, as John Searle defines it when he writes that "[s]ystems of representation, such as vocabularies and conceptual schemes generally, are human creations, and to that extent arbitrary. It is possible to have any number of different systems of representations for representing the same reality." ${ }^{14}$ According to this view, the concept of art is a human construct. I take that to mean that, like other human constructs, it can be expected to serve a purpose (or else it will be purposeless and can be discarded). ${ }^{15}$ We may ask ourselves what purpose or purposes it serves, and how well it performs.

As already intimated, my critical reflections about Levinson's remarks about the concept of art can be said to have paralleled my reservations towards Lamarque and Olsen's characterization of the literary stance. In both cases, I objected to the scant attention to relevant empirical fact: to actual literary practice, and to the actual employment of the word "art" among scholars, theorists, critics, and people in general. But perhaps Lamarque, Olsen, and Levinson would not, in effect, find my empirical deliberations relevant? Perhaps Lamarque and Olsen, in analysing the nature of the literary practice, do not conceive of themselves as obliged to take account of what readers of literature actually do and value? And perhaps Levinson does not regard his reflections about the concept of art as being restricted by considerations of how people - laypersons and various kinds of professionals - actually think and talk about what they call "art"? Perhaps Lamarque, Olsen, and Levinson all regard themselves as engaged in purely conceptual investigations?

I believe that this is a distinct possibility. Yet it seems to me that a purely conceptual investigation, liberated from concerns about how the corresponding words and ideas are employed by the community of speakers and writers of the language, will presuppose a special view of concepts. Concepts will have to be conceived of as enjoying a kind of existence that is - like that of material reality - ultimately independent of human conventions and symbolizations.

It is to such attitudes to concepts - common in analytical aesthetics $-{ }^{16}$ that I refer when I talk of objectivizing concepts. To concentrate on Levinson: I would say that he objectivizes the concept of art, implicitly portraying it as having some unexplained kind of existence independent of human minds and human conventions - and, of course, as being of unquestionable importance as a category of thought. I find this position problematic and even hard to comprehend. I would listen with interest to explanations from Levinson of how and where the concept of art exists 
according to him, and of the means by which we can gain knowledge of its contents. The same goes for Lamarque and Olsen and the idea of the literary practice.

\section{IV}

There are inner connections between the three problematic features of which I am speaking: the insufficient concern for relevant empirical facts (or the denial of the relevance of the facts in question), the tendency to objectivize concepts, and the tendency to believe in the existence of privileged perspectives on the world. The objectivizing of concepts is perhaps the key factor. If concepts are there - in a deeper sense than the one that people have already created a multitude of concepts which we are, in principle, free to reject or remodel - then it seems that conceptual relativity cannot really be in force. Concepts cannot be to some extent arbitrary, at least not the genuinely important concepts, and it will not be possible to have any number of different, defensible systems of representation for representing the same reality. There will be representations of the world couched in the right concepts; there will be the right take on the world, the privileged perspective on it. Further, if grasping the content of the right concepts is what matters, rational reflection, not empirical investigation, may seem to be what is called for.

The close relationship between belief in non-relative concepts and in the right take on the world is, I think, perceptible in Levinson's essay. I will however attempt to illustrate it further by aid of a third and last textual example: Noël Carroll's article "Art and Human Nature" (2004), ${ }^{17}$ where Carroll argues that art is universal and is explainable through reference to a common cause.

Carroll notes that some object to this idea on the premise that many other cultures lack the concept of art,

or, at least, that their concepts are so wildly different from the Western concept that they mark different phenomena. That is, once we recognize that the concepts that underwrite different artistic practices in different cultures are wildly nonconverging, we will realize that the phenomena we boldly suppose belong to the same class - and for that reason, we say, call for the same explanation - are really only a series of disjunct practices, best explained culturally and historically with attention to local detail, rather than something global, like our purportedly common humanity. ${ }^{18}$

Carroll does not tell us explicitly who the advocates of such divergent opinions are. He suggests, however, that the counter-arguments against 
his standpoint focus on the role of disinterested contemplation in the Western conception of art. Then he points out that the view of artworks "as things designed for disinterested, nonutilitarian contemplation" is in fact controversial within Western culture, and that the Western concept of art is broader and more diversified than that; for instance, there is much religious or political Western art. "In short," he concludes, "those who complain that other cultures do not share our concept of art and, therefore, that art, so-called, is not universal err because they take an impoverished view of what counts and has counted as art in Western culture."19

Carroll is in fact not content to argue that art is universal. He goes one step further, and maintains that other cultures share our concept of art. That was already implicit in the last quotation, but Carroll also states explicitly that "our operative conception of art coincides approximately to what we find elsewhere in other cultures" ${ }^{20}$ This is a further step, since the question of whether art in our sense is universal should not be confused with the question of whether other cultures share our concept of art. The art may be there, so to speak, according to our definition, but it may still clearly be the case that the other culture thinks differently than we do about the phenomena that we define as their art. ${ }^{21}$

Carroll defends the idea that other times and cultures share our concept of art basically by pointing out that the view of art as disinterested is not the only one in the Western tradition, and, conversely, that art serving religious or political purposes is also well known in the Western tradition. In my opinion, such a way of proceeding can never get us very far. What Carroll proves, if his facts are correct, is that there are similarities between some Western views of art and several other conceptualizations. I find it difficult to see how he gets from such observations to the conclusion that other cultures share our concept of art.

The question of whether or not other times and cultures share our present concept of art is, to a large extent, an empirical one. ${ }^{22}$ We can go through times and cultures and ask how they conceptualized the phenomena that we would like to classify as art. Then we can compare their conceptualizations with our concept of art, however we want to define it, and assess similarities and differences. This is precisely what Shiner did for the Western tradition from Antiquity up to today in The Invention of Art. In his view, older Western culture did not have our concept of art, hence the title of his book, but of course one may dispute Shiner's empirical findings and, regardless of empirical facts, one may disagree about whether two conceptualizations represent "the same" or "different" concepts. 
I am not in a position to say much about conceptualizations of nonliterary artistic phenomena in other cultures than our own, but I have at least some familiarity with the situation in the literary field. ${ }^{23}$ Before the modern period, in cultures with writing such as the classical Chinese, Indian, Western, et cetera, some texts were regarded as being of general cultural importance, other texts as being specialist texts ( for example, texts about medicine or about warfare), and still other texts were seen as representing trivial entertainment. Fiction was typically understood as trivial entertainment, and poetry as being of general cultural importance.

There were many concepts of genres and of types of text, but, as far as I know, no concepts closely resembling the modern concept of literature. In Western culture, the concept of poetry is no doubt the one that is most similar, but there are nevertheless important differences between the traditional concept of poetry and the modern concept of literature. ${ }^{24}$ Consequently, it is hard to see how one could successfully maintain that other cultures, including older Western culture, shared our concept of literature, despite the fact that those cultures had texts that we would now normally call literary. Since literature is an important part of art in the generic sense, this circumstance should already cast doubt on the idea that the other cultures shared what Carroll, like Levinson, refers to as "our concept of art". ${ }^{25}$

It is not really Carroll's conclusion, however, but his attitude to the phenomena discussed that is of interest for the theme of my present paper. Carroll does not, like Shiner and myself, show any interest in providing a unified exposition of how any other time or any other culture talked and thought about the phenomena in question. Thus he allows no perspective other than the one he calls the Western concept of art to emerge before his reader. Disconnected elements from other outlooks are introduced, but never the full perspectives which I would like to see compared with the Western conceptualizations.

I would say that Carroll by reasoning in this fashion not only effectively disregards the way in which other times and cultures viewed what we call their art, but that he also fosters the impression that our present concept of art provides the only valid perspective on the phenomena in question. It is not as if those phenomena could be viewed and described from many angles and for many purposes, each perspective bringing some interesting features to the fore while hiding or obscuring others. Carroll proceeds, I would say, as if our concept of art, or what he chooses to define as our concept of art, provided a privileged perspective on the phenomena.

This is combined with objectivizing the concept of art. Note, for ex- 
ample, Carroll's words about artworks or artistic practices as "phenomena we boldly suppose to belong to the same class - and for that reason, we say, call for the same explanation". Here, Carroll expresses himself as if classes exist independently of human conventions and as if we can make suppositions, correct or incorrect, about their membership. To me, classes are human constructs, like all conceptual phenomena - things that are created, not found, except of course in the sense that many classes have already been constructed and are already in cultural existence, for us to use, discard, or remake.

Like Levinson, Carroll asserts that the Western concept of art can be applied to cultures other than our own, ${ }^{26}$ but he also maintains that art is universal. The criteria for classifying something as art suggested by Carroll are relatively loose. He says that "there are certain very frequently recurring features in a great deal of what are called artworks across cultures, including their embodiment in a sensuous medium that calls for an imaginative response to their decorative, representational, emotive, and symbolic properties" and adds that "these things are typically the product of the application of skills, acquired from a tradition, and they address both feeling and cognition, often affording pleasure". ${ }^{27}$ For my part, being a conceptual relativist, I would say that whether or not art will emerge as universal partly depends on how you define "art". That will be a question not only of what exists in cultural reality but also of how you choose to represent it. In a definition built around Carroll's criteria, art would indeed probably turn out to be universal. A more interesting question to me, however, is why this should be considered a fruitful way of constructing the concept of art.

Carroll says nothing about that latter question, probably because he views the whole matter differently. When he discusses whether or not art is universal, I get the impression that he thinks of this almost as being a question of fact, as if there are things that simply are art, and that the thesis of their universal occurrence can be verified or falsified. He does not seem to believe that there are merely things which we call art, for reasons whose respectability can always, in principle, be questioned.

\section{V}

Before concluding, I would like to add three reservations or supplementary comments.

Firstly, each specimen of analytical aesthetics is naturally different and will have to be judged on its own merits. I certainly do not pretend to have described features that can be found everywhere in the tradition. 
Yet I believe that the phenomena which I have discussed are relatively widespread - the list of examples could easily have been made quite extensive - and the authors discussed are some of the best-known thinkers in the field.

Secondly, I do not wish to claim that my observations are very original. For instance, in his article "Why Philosophy of Art Cannot Handle Kissing, Touching, and Crying" (2003) Nicholas Wolterstorff criticizes analytical philosophy basically for what I have called its objectivizing of concepts and its belief in privileged perspectives on the world. ${ }^{28} \mathrm{He}$ emphasizes the lack of reflexivity found in analytical philosophy, its lack of awareness of the fact that a work of philosophy represents an intervention in reality, performed from a certain perspective and in a given historical situation. Wolterstorff writes that the "analytical philosopher talks and acts as if the questions he asks, concerning the analysis of concepts and the entailments among propositions, were located in some Platonic heaven of philosophical problems" and that analytical philosophers "typically ... do not reflect on why they ... ask the questions they do ask and use the concepts they do use. They are unreflective about their own intellectual, social, and political location. They are that because they do not think it is relevant. Philosophy, if done properly, is not perspectival but objective; it tells how things look from nowhere." ${ }^{29}$

Third, and lastly: though I have said a good deal about aspects that I find problematic, my paper is certainly motivated by a positive interest in analytical aesthetics. My own area of specialization is something I usually call fundamental literary theory, and I have learned much from analytical aesthetics, decade after decade. Unlike the majority of theorists within literary studies, which is my own subject, most analytical aestheticians have a genuine theoretical interest in the overall functioning and the possible value of what we vaguely refer to as literature. In addition, the average analytical aesthetician also has much greater technical competence than the average literary theorist when it comes to handling abstractions and organizing ideas and statements into coherent arguments. For these and other reasons, the future of analytical aesthetics is important to me. Furthermore I cannot actually see how the reforms that I implicitly argue for could be alien to its nature. People like John Searle, Larry Shiner, and Nicholas Wolterstorff can be said to speak, to a greater or lesser extent, from within the analytic-philosophical tradition itself. ${ }^{30}$ 


\section{Notes}

1. Peter Lamarque and Stein Haugom Olsen, Truth, Fiction, and Literature: A Philosophical Perspective (Oxford: Clarendon Press, 1994), p. 256.

2. See, for example, ibid., p. viii (autonomy), p. 369 (we should be "ready to abandon the notion that literature has a direct truth-seeking link with the world"), and Chapter 16.

3. Michael Charlton et al., Ergebnisse der Freiburger Telefonumfrage zu Lesestrategien erwachsener Leserinnen und Leser von Romanen, Forschungsberichte des Psychologischen Instituts der Albert-Ludwigs-Universität Freiburg i. Br. Available online at www.psychologie.uni-freiburg.de/pi-zentral/fobe-files/157.pdf.

4. Ibid., Appendix.

5. These data are not in the research report. I thank Michael Charlton for permitting me to see and refer to his files with overviews of the data. Thanks also to Madeleine Jeanneau for helping me access the files.

6. See Dagmar Hintzenberg, Siegfried J. Schmidt, and Reinhard Zobel, Zum Literaturbegriff in der Bundesrepublik Deutschland (Braunschweig and Wiesbaden: Friedr. Vieweg \& Sohn, 1980), p. 71, and Jofrid Karner Smidt, Mellom elite og publikum: littercer smak og litteraturformidling blant bibliotekarer i norske folkebibliotek (Oslo: Unipub forlag, 2002), esp. p. 113.

7.Cf. H.W.J.M. Miesen, "Predicting and Explaining Literary Reading: An Application of the Theory of Planned Behavior", Poetics 31 (2003), pp. 189-212, at pp. 195 and 201.

8. Paul Oskar Kristeller, “The Modern System of the Arts" (1951-52), in Kristeller's Renaissance Thought II: Papers on Humanism and the Arts (New York: Harper \& Row, 1965); Larry A. Shiner, The Invention of Art: A Cultural History (Chicago and London: University of Chicago Press, 2001).

9. Jerrold Levinson, "Extending Art Historically" (1993), in Levinson's The Pleasures of Aesthetics: Philosophical Essays (Ithaca and London: Cornell University Press, 1996).

10. Ibid., pp. 153-54.

11. My generalizations about the current use of the word "literature" in the following are a condensed version of the more detailed and better referenced account in my article "The Concept of Literature: A Description and an Evaluation", in From Text to Literature: New Analytic and Pragmatic Approaches, ed. Stein Haugom Olsen and Anders Pettersson (London: Palgrave Macmillan, 2005).

12. Webster's Ninth New Collegiate Dictionary (Springfield, Mass.: MerriamWebster Inc., Publishers, 1989), pp. 697-98.

13. The American Heritage Dictionary of the English Language, 4th ed. (Boston and New York: Houghton Mifflin Company, 2000), p. 100. 
14. John R. Searle, The Construction of Social Reality (New York: Free Press, 1995), p. 151.

15. By this, I do not mean to deny that, as Ian Hacking puts it, "we cannot help but sort many things as we do: we are, it seems, made to sort things much as we do" - Ian Hacking, Historical Ontology (Cambridge, Mass. and London: Harvard University Press, 2002), p. 98. Some very basic concepts may be hard-wired into our organisms; however concepts like 'literature', 'art', et cetera can hardly be supposed to belong to that kind.

16. For example, where thinking about the concept of art is concerned, Levinson is no exception. The idea that the concept of art should have a purpose, and that its value needs a motivation, are basically absent from such standard accounts as Stephen Davies's "Definitions of Art", in The Routledge Companion to Aesthetics, ed. Berys Gaut and Dominic McIver Lopes (London and New York: Routledge, 2001), and Robert Stecker's "Definition of Art", in The Oxford Handbook of Aesthetics, ed. Jerrold Levinson (Oxford: Oxford University Press, 2003), even if it is true that Davies touches on the question of why the things that we define may be important to us (pp. 169-70) and that Stecker, more importantly, at the end of his article, raises such questions about the definition of "art" as "What should we hope to achieve with such a definition?" (p. 152).

17. Noël Carroll, "Art and Human Nature", Journal of Aesthetics and Art Criticism 62 (2004).

18. Ibid., p. 97.

19. Ibid., pp. 97 and 98 respectively.

20. Ibid., p. 98.

21. Carroll's criticism of "those who complain that other cultures do not share our concept of art and, therefore, that art, so-called, is not universal" makes it seem as if he confounds the two issues or misconstrues the (lack of) relationship between them. Art may certainly be universal even if other cultures do not share our concept of art; however Carroll apparently believes that he has to argue that other cultures share our concept of art if he is to save the universality of art.

22. This is not the exact question that Carroll poses, since he takes it for granted that earlier Western culture shared our present Western concept of art. I am thus, for a moment, raising a somewhat wider issue.

23. More evidence for the following account can be found in Notions of Literature across Times and Cultures, ed. Anders Pettersson (Berlin and New York: Walter de Gruyter, 2006), especially in my "Introduction: Concepts of Literature and Transcultural Literary History", pp. 6-8, and in the sources cited there.

24. "The" traditional concept of poetry is certainly not a unitary phenomenon, nor is "the" modern concept of literature. What I have in mind are differences such as, for instance, the fact that poetry was most commonly associated with 
verse and the fact that fiction, central to the modern concept of literature, did not typically form part of poetry in the traditional sense.

25. Carroll, p. 98.

26. There is however a difference between Levinson and Carroll: Levinson is speaking of the (supposedly unifiable) present-day Western concept of art while Carroll is referring to the (supposedly unifiable) time-neutral Western concept of art.

27. Carroll, p. 98.

28. Nicholas Wolterstorff, "Why Philosophy of Art Cannot Handle Kissing, Touching, and Crying", Journal of Aesthetics and Art Criticism 61 (2003).

29. Ibid., pp. 20-21.

30. The article is a revised and slightly extended version of a paper read in Oslo at the 2005 annual conference of the Nordic Society of Aesthetics. I am grateful to the two anonymous referees of this journal for their constructive criticism, and I wish to thank Pat Shrimpton for checking my English. 